\title{
Proceso tradicional de aderezo de aceitunas verdes de mesa. Racionalización del cocido
}

\author{
Por S. Jaramillo Carmona ${ }^{a, b^{*}}$, A. de Castro ${ }^{b}$ y L. Rejano Navarro \\ ${ }^{a}$ Coop. Agrícola Ntra. Sra. de las Virtudes SCA (NSV, SCA). Apartado de correos 21, \\ 41540 La Puebla de Cazalla, Sevilla

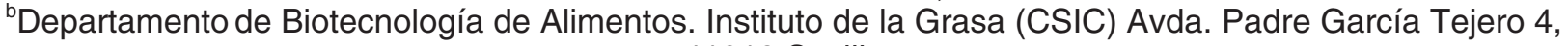 \\ 41012 Sevilla \\ ( ${ }^{*}$ Autor para la correspondencia: smaria@ cica.es)
}

\section{RESUMEN}

Proceso tradicional de aderezo de aceitunas verdes de mesa. Racionalización del cocido.

Las aceitunas Manzanillas, para su elaboración estilo español, precisan de un periodo previo de reposo de los frutos antes del cocido o tratamiento alcalino con $\mathrm{NaOH}$. Este periodo de reposo evita la rotura y desprendimiento de epidermis de los frutos pero, al mismo tiempo, provoca un aumento en el número de aceitunas con manchas superficiales y, consecuentemente, pérdida de calidad del producto. Los objetivos del presente trabajo fueron investigar, a escala industrial, alternativas al reposo previo; concretamente, la utilización de soluciones alcalinas de baja concentración antes del cocido y realizar este último con soluciones a temperatura reducida. Se analizaron los parámetros fundamentales de los procesos fermentativos obtenidos en cada caso y se determinó la calidad comercial de los productos finales. Los resultados obtenidos indican que ambas modificaciones constituyen alternativas al tratamiento tradicional con las que se obtienen productos de igual o superior calidad.

PALABRAS CLAVE: Aceitunas de mesa - Calidad - Cocido - Lejías frías - Precocido - Reposo.

\section{SUMMARY}

Traditional process of green table olives. Rationalization of alkaline treatment.

In order for olives of the Manzanilla variety to be produced as Spanish-style, they require a previous storage period before their alkaline treatment with $\mathrm{NaOH}$. This holding time prevents the breakage and shedding of the fruit epidermis, but at the same time, causes an increase in the number of olives with surface blemishes and, consequently, loss in product quality. The objectives of this work were to investigate, at industrial scale, different alternatives to the holding period; specifically, the use of low-concentration alkaline solutions before the real alkaline treatment, and the use of alkaline solutions at low temperatures for this alkaline treatment. Basic parameters of the fermentative processes carried out in every treatment were monitored, and commercial quality of the final product was ascertained. The results indicate that both modifications are alternatives to the traditional treatment, and the products obtained applying these modifications have the same or higher quality than those obtained by the traditional process.

KEY-WORDS: Cold lye - Holding time - Lye - Pre-lye Quality - Table olives.

\section{INTRODUCCIÓN}

La aceituna de mesa es un producto de gran importancia económica y social en España, siendo el primer país productor de la UE con 485.540 t en la campaña $2008 / 2009$, y destinando más del $49 \%$ a la exportación, por un valor de 544 millones de euros (AAO, 2010). Entre los distintos tipos de aceituna de mesa, las verdes estilo español son las más comercializadas en España. Su proceso de elaboración es relativamente sencillo: los frutos se tratan con una solución alcalina de hidróxido sódico ("cocido"), seguido de un lavado con agua y posteriormente se colocan en una salmuera donde sufren una fermentación láctica. El procedimiento de cocido provoca la hidrólisis de la oleuropeína responsable del amargor de las aceitunas, propiciando que, tras lavar con agua para eliminar el exceso de $\mathrm{NaOH}$, a los pocos días se desarrolle en las salmueras una población microbiana de bacterias lácticas y levaduras, que persiste hasta el final de la fermentación y que proporciona las características tan valoradas y peculiares de las aceitunas estilo español (Rodríguez de la Borbolla y Rejano Navarro, 1979). La variedad Manzanilla es la más difundida internacionalmente como aceituna de aderezo debido a su productividad y calidad del fruto, representando más del $70 \%$ de la producción total. Esta variedad, tras ser recolectada, precisa de uno o dos días de reposo previo, especialmente al principio de la campaña, para evitar que el posterior tratamiento con hidróxido sódico provoque la rotura y el desprendimiento de la piel, efecto conocido como "despellejado". Este tiempo de espera o reposo provoca una disminución de la calidad del producto final debido a que comienzan procesos degradativos derivados de la elevada actividad fisiológica de los frutos, además de aumentar el número y grado de aceitunas manchadas o con diversos defectos en la epidermis, defectos que se agrupan bajo la denominación de "molestado" de las aceitunas. El reposo provoca, además, una disminución del peso de las mismas de un 5\% (Ben Shalom et al, 1977). 
Por otra parte, al principio de la campaña (septiembre), cuando la temperatura ambiente es muy elevada, el cocido de las aceitunas suele resultar más enérgico de lo normal y se producen problemas de despellejado, los frutos resultan blandos, rompen al deshuesar y resulta una alta lejía residual (Rodríguez de la Borbolla y Rejano Navarro, 1978). Además, esto tiene como consecuencia unos altos valores de $\mathrm{pH}$ durante la fermentación que facilitan el desarrollo de posibles alteraciones y dificultan una buena conservación a largo plazo. Entre las distintas alteraciones que se ven favorecidas por temperaturas excesivamente altas al comienzo de la fermentación, se encuentra la conocida como "alambrado". El alambrado se manifiesta por la aparición de fisuras externas en los frutos acompañadas por huecos o bolsas de gas en la parte de pulpa inmediatamente adyacente a las fisuras. Está provocado por una excesiva liberación de gas consecuencia del metabolismo microbiano, fundamentalmente por Enterobacteriáceas (de la Borbolla y Alcalá et al., 1960).

Todo ello tiene graves repercusiones económicas para la industria, pues se produce una importante depreciación de los frutos, aumentando el porcentaje de aceitunas molestadas en algunos casos hasta un $18 \%$, además de incrementarse los gastos de producción para solucionar las posibles alteraciones que surjan, como problemas de alambrado, despellejado y vejigas, entre otras. Estas alteraciones pueden llegar a alcanzar hasta un $50 \%$ de aceitunas que pasan de categoría $1^{\text {a }}$ a $2^{a}$, lo que se traduce en más de 4 millones de euros de pérdidas sobre un volumen de aceitunas de 15.000 toneladas. Por tanto, el poder eliminar este tiempo de reposo o espera, sin que se produzca despellejado ni alteraciones, es de gran importancia.

Para evitar estos inconvenientes, en los últimos años se han desarrollado varias alternativas. Una de ellas consiste en cambiar el reposo por un tratamiento previo (precocido) con hidróxido sódico diluido durante al menos 3 horas. Otra modificación consiste en disminuir la energía de tratamiento de las aceitunas mediante una reducción de la temperatura de la lejía de cocido, manteniendo una concentración mínima necesaria para obtener un producto adecuado. Aunque estas variaciones son aplicadas por algunas industrias de forma empírica desde hace pocos años (Rejano Navarro et al., 2008), no se conocen estudios científicos que demuestren su efectividad a escala industrial, especialmente en relación con el cocido a baja temperatura.

Los objetivos del presente trabajo han sido investigar, a escala industrial, la evolución de los procesos fermentativos $-\mathrm{y}$ la calidad del producto final obtenido en cada caso- cuando se emplean lejías diluidas previas al cocido y cuando se realizan cocidos con lejías a baja temperatura.

\section{MATERIALES Y MÉTODOS}

\subsection{Variedad de aceitunas y tratamientos aplicados}

Los ensayos se realizaron a nivel industrial (fermentadores de $15.000 \mathrm{~kg}$ de capacidad) y con la variedad Manzanilla por ser la más difundida internacionalmente y la que más problemas presenta, pues precisa periodo de reposo para evitar el despellejado. El estudio se llevó a cabo durante dos campañas consecutivas, empleando aceitunas de la misma procedencia en todos los ensayos. El número de muestras estudiadas fue de cuatro fermentadores para cada tratamiento (dos por campaña). Los valores corresponden a la media de cuatro valores y su desviación estándar.

Se realizaron cuatro tratamientos diferentes (Tabla 1). El testigo con reposo (proceso tradicional) consistió en aceitunas que se mantuvieron las 48 horas requeridas previas para evitar el despellejado y fueron después cocidas a temperatura ambiente (Tratamiento $\mathrm{R}$ ). Se añadió otra serie con reposo en la que las aceitunas, además de mantenerse 48 horas antes del cocido, posteriormente fueron cocidas con lejía a baja temperatura, $18^{\circ} \mathrm{C}$ (Tratamiento $\mathrm{R}+\mathrm{F}$ ). En una tercera serie, las muestras fueron sometidas a un tratamiento previo con lejías diluidas, operación denominada precocido, y posteriormente cocidas con lejía a $18^{\circ} \mathrm{C}$ (Tratamiento $\mathrm{P}$ ). Una última serie no incluía reposo ni precocido, realizándose su tratamiento alcalino con lejía a $18^{\circ} \mathrm{C}$ (Tratamiento $\left.\mathrm{F}\right)$.

Tabla 1

Características de los procesos previos y de los cocidos en cada tratamiento

\begin{tabular}{|c|c|c|c|c|c|c|}
\hline \multirow[t]{2}{*}{ Tratamiento } & \multicolumn{3}{|c|}{ Reposo o Precocido } & \multicolumn{3}{|c|}{ Cocido } \\
\hline & $\begin{array}{l}\mathrm{NaOH} \\
(\% \mathrm{p} / \mathrm{v})\end{array}$ & $\begin{array}{l}\text { Tiempo } \\
\text { (h) }\end{array}$ & $\begin{array}{c}\text { Temperatura } \\
\left({ }^{\circ} \mathrm{C}\right)\end{array}$ & $\begin{array}{l}\mathrm{NaOH} \\
(\% \mathrm{p} / \mathrm{v})\end{array}$ & $\begin{array}{c}\text { Tiempo } \\
\text { (h) }\end{array}$ & $\begin{array}{c}\text { Temperatura } \\
\left({ }^{\circ} \mathrm{C}\right)\end{array}$ \\
\hline Reposo (R) & - & 48 & Ambiente & $1,56 \pm 0,04^{(a)}$ & $7,0 \pm 0,4$ & $25 \pm 1,2$ \\
\hline Reposo+Frío (R+F) & - & 48 & Ambiente & $1,56 \pm 0,02$ & $7,7 \pm 0,6$ & $18 \pm 1,6$ \\
\hline Precocido $(\mathrm{P})$ & $0,24 \pm 0,0$ & $3,0 \pm 0,0$ & $25 \pm 0,8$ & $1,56 \pm 0,01$ & $7,3 \pm 0,6$ & $18 \pm 0,8$ \\
\hline Frío (F) & - & - & - & $1,60 \pm 0,20$ & $7,0 \pm 0,1$ & $18 \pm 1,1$ \\
\hline
\end{tabular}

\footnotetext{
(a) Valor medio \pm error estándar de cuatro medidas.
} 
Una vez realizadas, en su caso, las operaciones previas de reposo o precocido, se procedió al tratamiento alcalino de las aceitunas. El tiempo necesario para un adecuado cocido se determinó en cada partida midiendo el grado de penetración del hidróxido sódico en la pulpa de la aceituna. A continuación, se realizó un lavado con agua y, pasado el tiempo necesario, las aceitunas se colocaron en la salmuera de fermentación. Para el seguimiento del proceso fermentativo, se tomaron muestras de salmuera en los primeros días de la fermentación y cada semana durante otros 21 días. Posteriormente, cada dos semanas durante un mes y finalmente, una al mes hasta los 240 días de fermentación.

\subsection{Equipo de frío}

Para disminuir la temperatura de las lejías se utilizó un equipo de frío VNEA 120-2S de la casa Plusinox. La enfriadora consiste en dos compresores de $60 \mathrm{CV}$ tipo semihermético alternativo, condensada por aire y con una potencia frigorífica de 198 KW.

\subsection{Control del proceso: análisis químicos y microbiológicos}

Periódicamente se realizaron determinaciones de $\mathrm{pH}$, acidez libre, acidez combinada y concentración de $\mathrm{NaCl}$, en cada fermentador. El pH de la salmuera se determinó usando un pHmetro Crison 2001. Para la acidez libre y combinada de la salmuera se siguen las metodologías IOOC (1990): titulación con $\mathrm{NaOH}$ hasta color rosa persistente (Iibre) y con $\mathrm{HCl}$ (combinada) hasta $\mathrm{pH}$ 2.6. La concentración de $\mathrm{NaCL}$ en salmuera se efectuó con la determinación del ión cloruro mediante valoración con nitrato de plata (Durán et al. 1994).

Para el análisis microbiológico se sembraron las muestras de salmuera $-y$ sus diluciones decimales en solución salina 0,9\%- usando un sembrador en espiral (Don Whitley Sci. Ltd., Model Wasp 2, Shirpley, UK). Se utilizaron diferentes medios de cultivo para conocer la población de Enterobacteriáceas (VRBG agar, Merck), bacterias lácticas (MRS agar, Oxoid sin/con $0,02 \%$ de azida sódica Sigma), y levaduras (OGYE agar, Oxoid). Tras incubación a $32^{\circ} \mathrm{C}$ durante 48 o $72 \mathrm{~h}$, se calcularon las unidades formadoras de colonias por $\mathrm{mL}$ de salmuera (ufc/ $\mathrm{mL}$ ) desarrolladas en cada caso (de Castro y Brenes, 2001).

\subsection{Evaluación del molestado}

Se hizo una determinación del molestado o marcas superficiales por medio de un equipo automático ESCA200, marca Niltria, que permite realizar un control automático de las manchas presentes en la superficie de los frutos. El sistema se basa en una cámara que va tomando continuamente imágenes de los frutos que están pasando por los rodillos de transporte. Las imágenes son procesadas para determinar la categoría a la que pertenecen los frutos. A partir del contorno de los frutos éstos se clasifican en función del color, saturación, defectos, intensidad, calibre y forma. Este equipo facilita diversa información entre la que destaca el calibre medio; la distribución en porcentaje para la escala de calibres recogida en la Norma del Consejo Oleícola Internacional (COI, 2004); el porcentaje de morado considerando como tal el $25 \%$ del área agrupado en una vista; y el porcentaje de molestado considerando como tal los frutos con defectos en la epidermis superiores a $4 \mathrm{~mm}^{2}$.

\subsection{Control de calidad del producto final}

Además de la determinación instrumental del molestado, se estudiaron los defectos y tolerancias (límites de aceptación o rechazo) que presentaron las aceitunas para su clasificación en las categorías comerciales correspondientes recogidas en la legislación vigente (BOE, 2001). Se llevó a cabo la evaluación global del color y del molestado de forma visual y con los criterios industriales durante todo el proceso de aderezo. También se determinó el porcentaje de alambrado, defecto muy importante en la comercialización de aceitunas, separando manualmente los frutos con fisuras externas visibles del resto sin esta alteración.

\subsection{Prueba del deshuesado}

Se pesó $1 \mathrm{~kg}$ de aceitunas y se deshuesaron con deshuesadora manual. Se contaron los huesos que han deshuesado bien quedando limpios, los que lo han hecho con pulpa adherida, y aquellas aceitunas que se han roto. Teniendo en cuenta el número inicial de aceitunas de las que se ha partido, se determinó el porcentaje de huesos con pulpa y el de aceitunas rotas. Para calcular la cantidad de pulpa que se ha perdido con los huesos de las aceitunas que han deshuesado mal, se determinó el peso medio del hueso de las bien deshuesadas y de las que deshuesaron mal, determinándose la pérdida por diferencia.

\subsection{Análisis estadístico}

Los datos presentados son el resultado de dieciséis fermentadores a lo largo de 2 campañas consecutivas. Los datos fueron analizados estadísticamente utilizando ANOVA del software Statgraphics (versión 5.1). Se usó el test de Duncan para comparar si las medias de los valores obtenidos eran estadísticamente diferentes, con una significación de $p<0,05$.

\section{RESULTADOS Y DISCUSIÓN}

\subsection{Evolución del proceso fermentativo en los diferentes tratamientos}

Los resultados de las características físico-químicas más importantes en relación con la fermen- 
tación obtenida con cada tratamiento se presentan en la Tabla 2 ( $\mathrm{pH}$ y acidez combinada) y Figura 1 (acidez libre). El control del pH durante los meses que tuvo lugar el proceso fermentativo mostró que, en todos los casos, tuvo lugar un descenso impor- tante indicativo de que la fermentación evolucionó normalmente (Fernández Díez et al., 1985). No obstante, se encontraron algunas diferencias entre tratamientos con distinto grado de significación. En la fermentación de aceitunas verdes de mesa, es

Tabla 2

Evolución de los valores de pH y de acidez combinada (eq/L) durante el período de ensayo

\begin{tabular}{ccccc}
\hline Días & Reposo (R) & $\begin{array}{c}\text { Reposo+Frío } \\
(\mathbf{R + F})\end{array}$ & Precocido (P) & Frío (F) \\
\hline & & & $\mathbf{p H}$ & \\
1 & $7,53 \pm 0,60 \mathrm{a}$ & $7,46 \pm 0,09 \mathrm{a}$ & $7,92 \pm 0,07 \mathrm{a}$ & $8,70 \pm 0,060 \mathrm{~b}$ \\
5 & $5,63 \pm 0,10 \mathrm{ab}$ & $5,46 \pm 0,08 \mathrm{a}$ & $5,71 \pm 0,1 \mathrm{bc}$ & $5,79 \pm 0,06 \mathrm{c}$ \\
10 & $5,42 \pm 0,04 \mathrm{a}$ & $4,82 \pm 0,14 \mathrm{a}$ & $4,83 \pm 0,17 \mathrm{a}$ & $4,89 \pm 0,62 \mathrm{a}$ \\
15 & $4,52 \pm 0,04 \mathrm{a}$ & $4,77 \pm 0,23 \mathrm{ab}$ & $4,74 \pm 0,06 \mathrm{ab}$ & $4,58 \pm 0,14 \mathrm{~b}$ \\
25 & $4,55 \pm 0,05 \mathrm{a}$ & $4,68 \pm 0,16 \mathrm{ab}$ & $4,75 \pm 0,03 \mathrm{~b}$ & $4,59 \pm 0,12 \mathrm{ab}$ \\
35 & $4,51 \pm 0,02 \mathrm{a}$ & $4,69 \pm 0,04 \mathrm{~b}$ & $4,69 \pm 0,02 \mathrm{~b}$ & $4,52 \pm 0,09 \mathrm{a}$ \\
50 & $4,43 \pm 0,04 \mathrm{a}$ & $4,62 \pm 0,30 \mathrm{a}$ & $4,59 \pm 0,09 \mathrm{a}$ & $4,45 \pm 0,06 \mathrm{a}$ \\
80 & $4,22 \pm 0,05 \mathrm{a}$ & $4,55 \pm 0,03 \mathrm{~b}$ & $4,39 \pm 0,08 \mathrm{c}$ & $4,28 \pm 0,02 \mathrm{a}$ \\
120 & $4,06 \pm 0,05 \mathrm{a}$ & $4,52 \pm 0,08 \mathrm{c}$ & $4,24 \pm 0,06 \mathrm{~b}$ & $4,12 \pm 0,05 \mathrm{ab}$ \\
160 & $3,91 \pm 0,01 \mathrm{a}$ & $4,22 \pm 0,1 \mathrm{~b}$ & $4,18 \pm 0,07 \mathrm{a}$ & $3,98 \pm 0,07 \mathrm{a}$ \\
200 & $3,91 \pm 0,01 \mathrm{a}$ & $4,10 \pm 0,09 \mathrm{~b}$ & $3,95 \pm 0,03 \mathrm{a}$ & $3,89 \pm 0,05 \mathrm{a}$ \\
240 & $3,80 \pm 0,02 \mathrm{a}$ & $4,22 \pm 0,27 \mathrm{~b}$ & $3,80 \pm 0,06 \mathrm{a}$ & $3,75 \pm 0,05 \mathrm{a}$ \\
& & Acidez combinada & \\
10 & $0,096 \pm 0,006 \mathrm{a}$ & $0,110 \pm 0,006 \mathrm{a}$ & $0,093 \pm 0,001 \mathrm{a}$ & $0,093 \pm 0,004 \mathrm{a}$ \\
25 & $0,095 \pm 0,002 \mathrm{a}$ & $0,112 \pm 0,003 \mathrm{a}$ & $0,096 \pm 0,011 \mathrm{a}$ & $0,093 \pm 0,003 \mathrm{a}$ \\
50 & $0,093 \pm 0,002 \mathrm{a}$ & $0,109 \pm 0,003 \mathrm{a}$ & $0,105 \pm 0,004 \mathrm{a}$ & $0,085 \pm 0,001 \mathrm{a}$ \\
125 & $0,086 \pm 0,003 \mathrm{a}$ & $0,108 \pm 0,003 \mathrm{~b}$ & $0,095 \pm 0,001 \mathrm{ab}$ & $0,080 \pm 0,003 \mathrm{a}$ \\
200 & $0,084 \pm 0,004 \mathrm{a}$ & $0,100 \pm 0,002 \mathrm{~b}$ & $0,091 \pm 0,001 \mathrm{ab}$ & $0,079 \pm 0,001 \mathrm{a}$ \\
240 & $0,081 \pm 0,002 \mathrm{a}$ & $0,099 \pm 0,002 \mathrm{a}$ & $0,088 \pm 0,003 \mathrm{a}$ & $0,080 \pm 0,001 \mathrm{a}$ \\
\hline
\end{tabular}

a Valor medio \pm error estándar de cuatro medidas. En cada efecto, los valores de una fila con letras diferentes son significativamente distintos $(p<0,05)$.

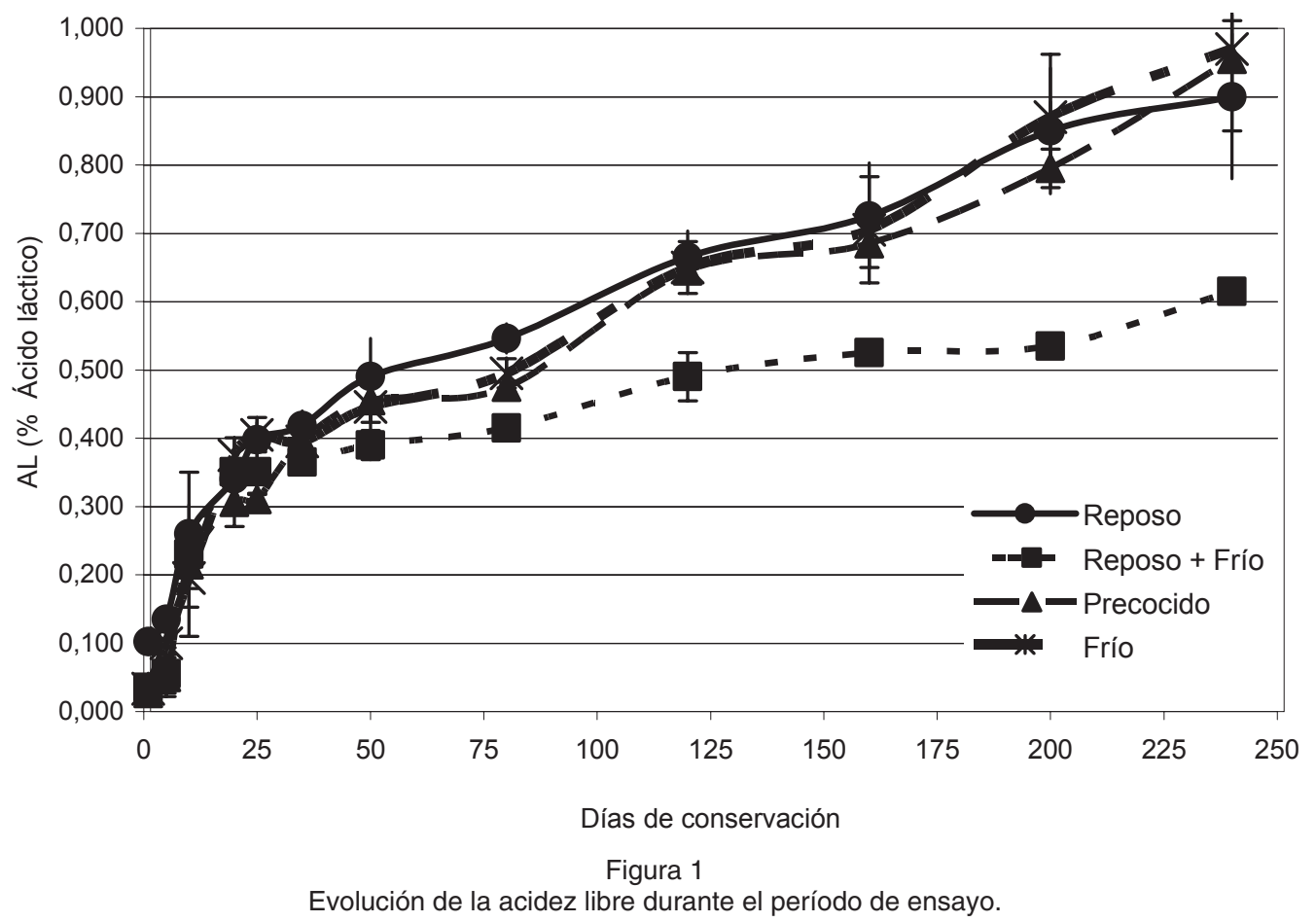


importante alcanzar valores de $\mathrm{pH}$ inferiores a 4,5 en el menor tiempo posible, ya que dicho valor inhibe el desarrollo de bacterias alterantes, tanto las responsables del alambrado (de la Borbolla y Alcalá et al., 1960), como de otras alteraciones (Montaño et al., 1992). En los tratamientos estudiados, aunque el descenso de $\mathrm{pH}$ durante los primeros 10 días parecía más lento en los testigos con reposo tradicional, posteriormente presentaron mejor evolución, de forma que a los 35 días se alcanzó el valor 4,51 en ellos. Por el contrario, el tratamiento de reposo seguido de cocido con lejía fría, tuvo un inicio rápido como el resto los 10 primeros días pero, finalmente, no alcanzó valores inferiores a 4,5 hasta pasados 120 días, lo que implica cuatro meses con los frutos expuestos a posibles alteraciones. Esta evolución significativamente más desfavorable del tratamiento Reposo+Frío se ve confirmada por los valores de $\mathrm{pH}$ finales a los 240 días. No obstante, hay que resaltar que, en todos los casos, los valores finales de $\mathrm{pH}$ son aptos para una conservación adecuada del producto.

Los resultados de acidez combinada (Tabla 2) fueron semejantes en los cuatro ensayos y dentro de los márgenes adecuados, indicando que tanto el cocido como el lavado fueron correctos en todos los tratamientos (Fernández-Díez et al., 1985). De igual forma, los valores de concentración en cloruro sódico fueron adecuados en todos los tratamientos (datos no mostrados).

La acidez libre (Figura 1) experimentó un aumento exponencial durante los primeros 25 días de fermentación hasta alcanzar un valor medio cercano a $0,4 \%$, conforme con el descenso de $\mathrm{pH}$ observado. Posteriormente continuó aumentando de manera más lenta y variable entre los distintos tratamientos hasta el final de la fermentación y durante la conservación. En esta lenta evolución destacó la muestra Reposo + Frío, que se apartó claramente de la evolución similar que presentaron las restantes muestras, su valor fue manteniéndose menor en el tiempo hasta alcanzar una diferencia final de $0,30 \%$.

Por la relación directa que existe entre la acidez libre y el $\mathrm{pH}$ se explica claramente el mayor valor de $\mathrm{pH}$ que mantuvo la muestra $\mathrm{R}+\mathrm{F}$ a todo lo largo de su fermentación.

Los resultados obtenidos en el análisis microbiológico de las muestras (Tabla 3), indicaron la presencia en todos los tratamientos de las poblaciones de bacterias lácticas y levaduras necesarias para llevar a cabo el proceso fermentativo (Fernández-Díez et al., 1985), sin que puedan establecerse diferencias entre tratamientos. No se detectaron Enterobacteriáceas en ninguno de los casos (datos no mostrados).

\subsection{Calidad del producto final}

En cuanto a la evaluación de la calidad de las aceitunas, los resultados mostraron, efectivamente, el aumento tan importante en el porcentaje de aceituna molestada que se produjo durante el período de reposo (Figura 2). Así, mientras que en las aceitunas que fueron procesadas tras ser recolectadas y clasificadas (bien con tratamiento previo de precocido o bien con lejía fría) el molestado escasamente fue superior al $5 \%$, en el caso de las aceitunas que estuvieron $48 \mathrm{~h}$ de reposo (testigo o posteriormente tratadas con lejías frías), el porcentaje de frutos molestados superó el $20 \%$, alcanzándose incluso el $25 \%$. Si bien el tratamiento de cocido y posterior fermentación hace disminuir el porcentaje de aceitunas inicialmente manchadas, la cantidad de éstas al final del proceso fermentativo siguió siendo significativamente superior cuando hay reposo con respecto a los otros dos tratamientos (Figura 2). Según este defecto, el 93\% de las aceitunas tratadas previamente con lejías diluidas (Precocido) y el $96 \%$ de las cocidas con lejías a baja temperatura (Frío), se clasificaron dentro del gru-

Tabla 3

Población microbiana durante el proceso fermentativo

\begin{tabular}{ccccc}
\hline Días & Reposo (R) & $\begin{array}{c}\text { Reposo+Frío } \\
(\mathbf{R}+\mathbf{F})\end{array}$ & Precocido $(\mathbf{P})$ & Frío (F) \\
\hline & & \multicolumn{1}{c}{ Bacterias lácticas (ufc/mL) } \\
10 & $>1,0 \times 10^{6}$ & $>1,0 \times 10^{6}$ & $>1,0 \times 10^{6}$ & $>1,0 \times 10^{6}$ \\
35 & $1,0 \times 10^{6}$ & $1,0 \times 10^{6}$ & $1,0 \times 10^{6}$ & $2,0 \times 10^{6}$ \\
160 & $2,0 \times 10^{6}$ & $2,0 \times 10^{6}$ & $2,5 \times 10^{6}$ & $2,5 \times 10^{6}$ \\
240 & $3,1 \times 10^{6}$ & $2,5 \times 10^{6}$ & $2,8 \times 10^{6}$ & $3,0 \times 10^{6}$ \\
& & Levaduras (ufc/mL) & \\
10 & $4,1 \times 10^{3}$ & $3,1 \times 10^{3}$ & $4,0 \times 10^{3}$ & $4,0 \times 10^{3}$ \\
35 & $7,6 \times 10^{4}$ & $1,0 \times 10^{4}$ & $7,0 \times 10^{4}$ & $7,0 \times 10^{4}$ \\
160 & $2,3 \times 10^{4}$ & $3,7 \times 10^{4}$ & $5,0 \times 10^{5}$ & $1,0 \times 10^{5}$ \\
240 & $1,8 \times 10^{5}$ & $1,0 \times 10^{5}$ & $2,0 \times 10^{6}$ & $2,0 \times 10^{5}$ \\
\hline
\end{tabular}




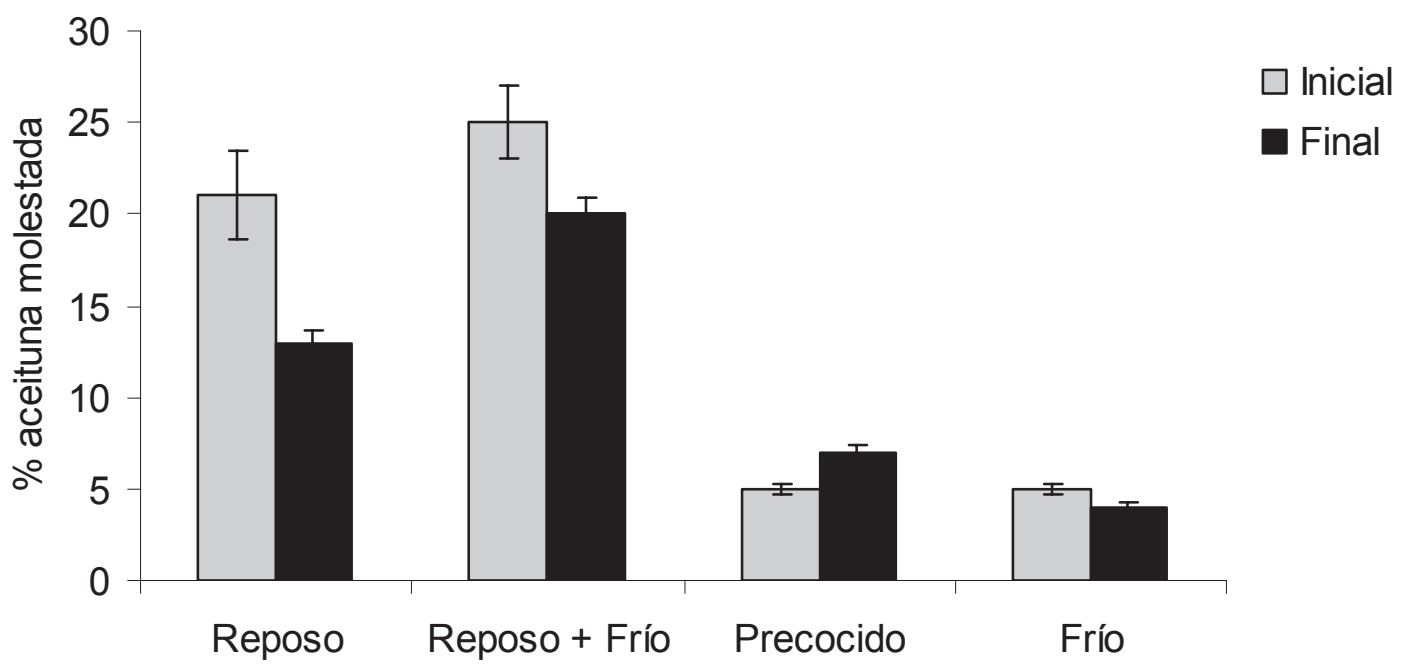

Figura 2

Porcentaje de aceituna molestada en cada tratamiento antes del cocido (Inicial) y concluida la fermentación (Final)

po primera categoría, mientras que las de reposo, bien sea el tradicional cocidas con lejías a temperatura ambiente, bien sean cocidas con lejías a baja temperatura, tenían un elevado porcentaje, $13 \%$ y $18 \%$ respectivamente, de aceitunas que ni siquiera podían ser comercializadas dentro de la categoría segunda.

En cuanto al porcentaje de aceitunas alambradas, los valores obtenidos se presentan en la Figura 3. Se observó que las muestras cocidas directamente en frío fueron las que presentaron el menor porcentaje de alambrado. Así, la clasificación de las aceitunas para este defecto, aunque no conozcamos que exista una relación directa entre ambos, fue semejante al defecto anterior; es decir, las muestras con reposo seguidas de un cocido a baja temperatura presentaron los porcentajes más elevados de aceitunas que no entran dentro de la categoría de segundas, mientras que las muestras tratadas previamente con un precocido y las cocidas directamente con lejías frías tenían una calidad muy superior, encuadrándose la mayoría de los frutos dentro de las categorías extra y primera.

En último lugar se realizó una prueba de deshuesado de las distintas experiencias. La Tabla 4 muestra los porcentajes de pulpa pegada al hueso y de aceitunas rotas. Se apreció que para la experiencia con reposo seguido de un cocido a baja temperatura se obtuvieron los mayores valores de pérdida de pulpa en el hueso y de aceitunas rotas, mientras que para las otras tres experiencias se tenían valores inferiores y semejantes en ambos parámetros, siendo de destacar la significativa reducción del número de aceitunas rotas con el cocido en frío. Estos valores se asocian a la energía del tratamiento alcalino inicial que depende de la madurez y del tamaño medio de las aceitunas, de

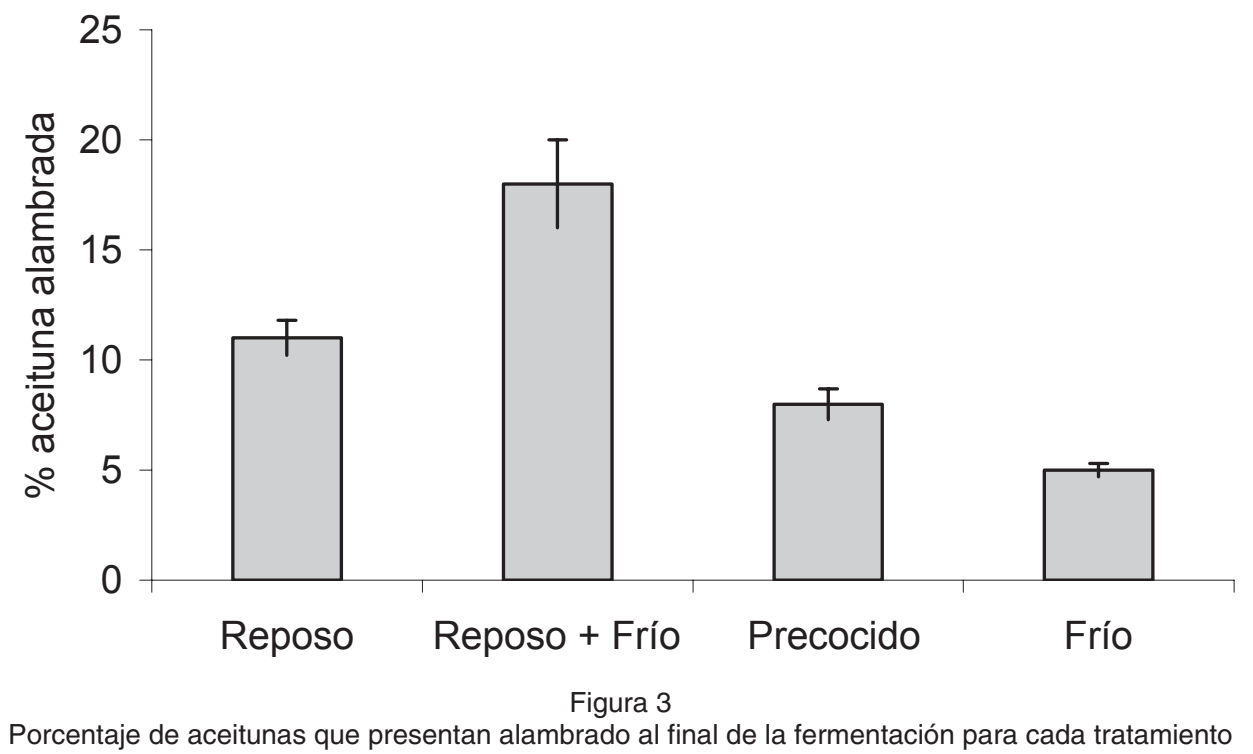


Tabla 4

Porcentaje de pulpa perdida y de aceitunas rotas en las pruebas de deshuesado realizadas en los distintos procesos de elaboración

\begin{tabular}{lcc}
\hline & \% Pulpa en hueso & \% Aceitunas rotas \\
\hline Reposo & $8.1 \pm 0,6 \mathrm{a}$ & $1,9 \pm 0,7 \mathrm{a}$ \\
Reposo+Frío & $11,6 \pm 0,7 \mathrm{~b}$ & $4,1 \pm 0,9 \mathrm{~b}$ \\
Precocido & $8,4 \pm 0,5 \mathrm{a}$ & $1,9 \pm 0,8 \mathrm{a}$ \\
Frío & $7,5 \pm 0,4 \mathrm{a}$ & $1,4 \pm 0,3 \mathrm{c}$ \\
\hline
\end{tabular}

a Valor medio \pm error estándar de cuatro medidas. En cada efecto, los valores de una columna con letras diferentes son significativamente distintos $(p<0,05)$.

la concentración de la lejía, de la temperatura a lo largo del cocido y, especialmente, del grado de penetración de dicha lejía hacia el hueso. En la Figura 4 se presenta la evolución de la temperatura de la lejía durante los distintos cocidos. Los tratamientos que presentaron temperaturas más altas durante todo el cocido fueron los dos que incluyeron reposo, tanto el testigo tradicional cuya lejía inicial estaba a $25^{\circ} \mathrm{C}(\mathrm{R})$, como el cocido con lejía a $18^{\circ} \mathrm{C}(\mathrm{R}+\mathrm{F})$. Probablemente, la permanencia de los frutos a temperatura ambiente durante 48 horas en ambos tratamientos implicó sobrecalentamientos de los mismos debido a su actividad fisiológica, lo que dio lugar a tratamientos de cocido más enérgicos en ellos. Las temperaturas más bajas durante todo el cocido se obtuvieron cuando las aceitunas se trataron directamente con lejía a $18^{\circ} \mathrm{C}$, sin ningún tratamiento previo de reposo ni de precocido.

Concluyendo, se han estudiado las características de la fermentación industrial de aceitunas preparadas con distintas modificaciones en etapas previas al cocido y se ha investigado, asimismo, el efecto de la temperatura de la lejía empleada en este tratamiento alcalino. Por la importancia económica que ello tiene, se han analizado parámetros de calidad fundamentales en el producto final obtenido en cada caso. Los resultados han demostrado que la práctica tradicional de reposo que se aplica en muchas ocasiones a las aceitunas Manzanillas, provoca los valores más elevados de frutos con manchas o marcas superficiales (aceitunas molestadas), así como superiores porcentajes de alambrado. Por el contrario, la operación denominada precocido, consistente en colocar los frutos en lejías de baja graduación durante tres horas, puede aplicarse en sustitución del reposo sin los efectos indeseables de éste. Se confirma así, que la colocación de aceitunas en lejías de baja graduación antes del cocido -estudiada anteriormente por Rejano Navarro et al. (2008) para evitar el molestado en Manzanillas recolectadas mecánicamente- es un método efectivo también para reducir el molestado en aceitunas sin reposo. Los mismos autores investigaron, a escala de laboratorio, los efectos del cocido con lejías a bajas temperaturas. En el trabajo que ahora se presenta, se ha podido confirmar a escala industrial que la utilización de lejías a $18^{\circ} \mathrm{C}$ para el cocido de aceitunas sin reposo previo, da lugar a productos finales con características superiores a las obtenidas con otros tratamientos: menor porcentaje de frutos alambrados, molestados o rotos al deshuesar.

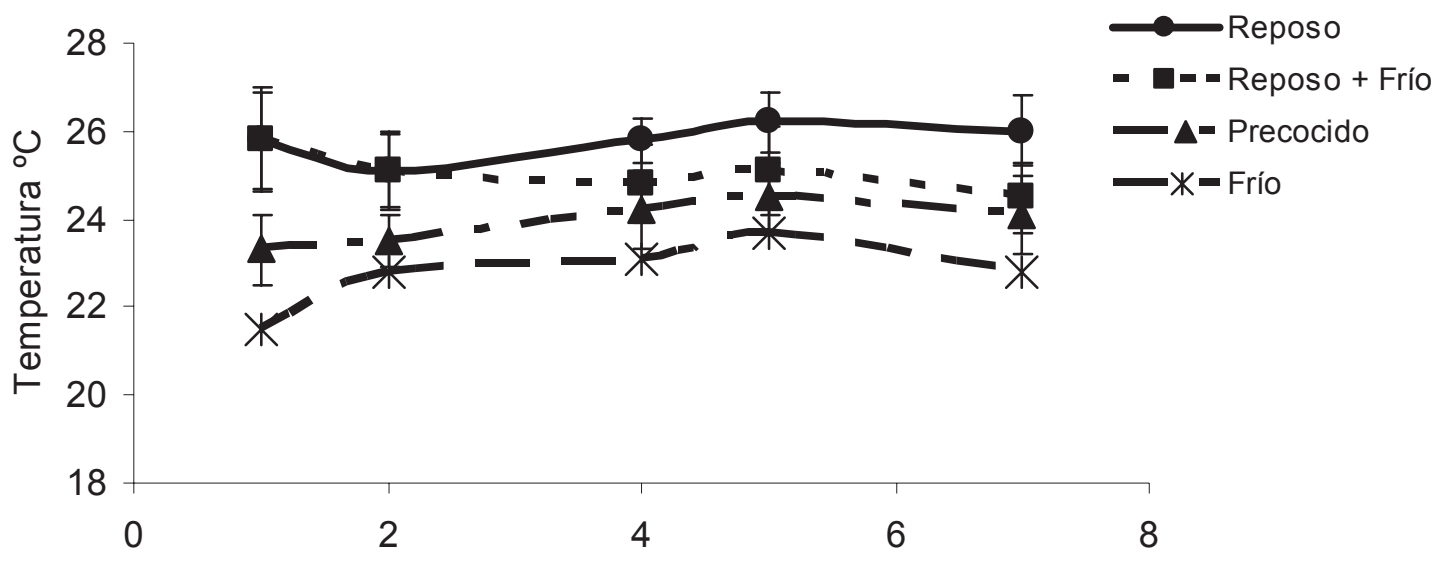

Horas cocido 


\section{AGRADECIMIENTOS}

Los autores quieren a agradecer al Ministerio de Educación y Ciencia, Programa Torres Quevedo y a la Coop. Agric. Nstr. Sra. de las Virtudes (NSV, $\mathrm{SAC}$ ) por la financiación y ayuda prestada en el desarrollo de este trabajo.

\section{REFERENCIAS}

AAO (Agencia para el Aceite de Oliva). 2010. http://aplicaciones.mapa.es/pwAgenciaAO/InfMercados Aceituna_BalanceAceituna.aao? opcion seleccionada $=4240 \&$ control acceso $=S \&$ idioma $=E S P$ Ministerio de Medio Ambiente y Medio Rural y Marino.

Ben-Shalom N, Kahn V, Harel E, Mayer AM. 1977. Catechol oxidase from green olives: Properties and partial purification. Phytochemistry 16, 1153-1158.

BOE. 2001. Boletín Oficial del Estado. REAL DECRETO 1230/2001, Reglamentación técnico-sanitaria para la elaboración, circulación y venta de las aceitunas de mesa, BOE 21 de noviembre 2001, 42587-42594.

COI. Consejo Oleícola Internacional.2004. Resolución № RES-2/91-IV/04, Norma comercial aplicable a las aceitunas de mesa. Consejo Oleícola Internacional, Madrid, 1-17.

De Castro A, Brenes M. Fermentation of washing waters of Spanish-style green olive processing. 2001. Process Biochem. 36, 797-802.

De la Borbolla y Alcalá JMR, Fernández Díez MJ, González Cancho F. 1960. Estudios sobre el aderezo de aceitunas verdes. XIX. Nuevas experiencias sobre el "alambrado". Grasas y Aceites 11, 256-260.

Durán MC, García P, Brenes M, Garrido, A. 1994. Lactobacillus plantarum survival in aerobic, directly brined olives. J. Food Sci. 59, 1197-1201.

Fernández-Díez MJ, de Castro R, Garrido A, GonzálezCancho F, González-Pellissó F, Nosti M, Heredia A, Mosquera IM, Rejano L, Durán MC, Sánchez F, García $\mathrm{P}$, de Castro A. 1985. Aceitunas tipo verde, en Biotecnología de la Aceituna de Mesa. Consejo Superior de Investigaciones Científicas, Madrid, España, 55-123.

IOOC. 1990. International Olive Oil Council. Technical Handbook: Table olive processing. IOOC, Madrid.

Montaño A, de Castro A, Rejano L, Sánchez A-H. 1992. Analysis of zapatera olives by gas and high-performance liquid chromatography. J. Chromatogr. 594, 259-267.

Rejano Navarro L, Sánchez-Gómez A-H, Vega Macías V. 2008. Nuevas tendencias en el tratamiento alcalino "cocido" de las aceitunas verdes aderezadas al estilo español o sevillano. Grasas y Aceites 59, 197-204.

Rodríguez de la Borbolla JM, Rejano Navarro L. 1978. Sobre la preparación de la aceituna estilo sevillano. El lavado de los frutos tratados con lejía. Grasas y Aceites 29, 281-91.

Rodríguez de la Borbolla JM, Rejano Navarro L. 1979. Sobre la preparación de la aceituna estilo sevillano. La fermentación I. Grasas y Aceites 30, 175-185.

Recibido: 23/11/10 Aceptado: 22/2/11 